\section{Introgressing Cold-tolerant Ogura Cytoplasm from Rapeseed into Pak Choi and Chinese Cabbage}

\author{
Douglas W. Heath ${ }^{1}$ and Elizabeth D. Earle ${ }^{2}$ \\ Department of Plant Breeding and Biometry, Cornell University, Ithaca, \\ NY 14853
}

\author{
Michael H. Dickson ${ }^{3}$ \\ Department of Horticultural Sciences, Cornell Agricultural Experiment Station, \\ Geneva, NY 14456
}

Additional index words. Brassica napus, Brassica campestris Chinensis Group, Brassica campestris Pekinensis Group, Ogura male sterility, somatic hybrid

\begin{abstract}
Cold-tolerant, Ogura male-sterile, somatic hybrid rapeseed (Brassica napus L.) lines were used as maternal parents in two independent introgression experiments. In one experiment, an atrazine-sensitive $B$. napus (aacc) somatic hybrid was crossed directly with a male-fertile pak choi (B. campestris Chinensis Group, aa) accession. Allotriploid (sac) progeny were then backcrossed to the recurrent pak choi parent. Forty-five percent of the progeny from the first backcross were determined to be diploids (aa). In the other experiment, an atrazine-resistant $B$. napus somatic hybrid was crossed first to a bridge line. Three additional backcross generations to Chinese cabbage (B. campestris Pekinensis Group) resulted in Chinese cabbage resistant to black rot (Xanthomonas campestris pv. campestris). These materials may be useful for production of $B$. campestris hybrid
\end{abstract} vegetable seed.

Cytoplasmic male sterility (ems) has contributed to efficient production of $\mathrm{F}_{1}$ hybrid seed in many crops (Hanson and Conde, 1985) and shows promise for Brassica breeding. The "Ogura" male-sterile cytoplasm was discovered in a variety of Japanese radish (Raphanus sativus L.; $n=9$ ) (Ogura, 1968) and was subsequently transferred to $B$. oleracea Botrytis Group $(n=9)$ and B. napus $(n=19)$ by backcrossing (Bannerot et al., 1974). Three problems existed in the initial B. napus material: 1) low-temperature chlorosis; 2) low nectar production; and 3) lack of good male fertility restoration (Rousselle, 1982). The lowtemperature chlorosis is probably caused by an incompatibility between the Raphanus chloroplasts and the Brassica nucleus (Jarl et al., 1989). The chlorosiscan lead to a reduction in seed yield, making such material unacceptable.

Problems with low-temperature chlorosis and poor nectary development have been cir-

Received for publication 13 May 1993. Accepted for publication 21 Oct. 1993. Paper no. 817 of the Dept. of Plant Breeding and Biometry, Cornell Univ. This research was supported in part by the United States-Israel Binational Agricultural Research and Development Fund (BARD) Grant no. I1443-88. The cost of publishing this paper was defrayed in part by the payment of page charges. Under postal regulations, this paper therefore must be hereby marked advertisement solely to indicate this fact.

'Former Postdoctoral Associate. Current address: Petoseed Co., 37437 State Hwy. 16, Woodland, CA 95695.

${ }^{2}$ Professor. To whom reprint requests should be addressed.

${ }^{3}$ Professor. cumvented through protoplasm fusion. Brassica napus plants with Brassica rather than Raphanus choroplasts were produced by fusion and exhibited no low-temperature chlorosis (cold tolerance). Fusion strategies included 1) resynthesis of $B$. napus by combining Ogura male-sterile $B$. oleracea with either atrazineresistant B. campestris (Jourdan et al., 1989) or atrazine-sensitive B. campestris (Heather, 1993); and 2) the production of $B$. napus cybrids (e.g., Pelletier et al., 1983; Stephenson, 1991).

Transfer of traits between B. napus (aacc) and $B$. campestris (aa) is often done by introgression. In Japan, such introgression is a standard rapeseed breeding technique (Shiga, 1970). Because B. campestris is generally recalcitrant in culture (Jourdan and Earle, 1989), introgression of traits into B. campestris is more efficient than protoplasm fusion. The objectives of this study were to 1) transfer cold-tolerant Ogura cms from somatic hybrid B. napus lines into pak choi and Chinese cabbage; and 2) incorporate black-rot resistance through introgression of selected $B$. napus and $B$. campestris lines with Chinese cabbage. In both cases, traits were introgressed from $B$. napus rather than $B$. campestris because only $B$. napus materials with the desired cytoplasm were available.

\section{Materials and Methods}

Plant materials and culture. Cold-tolerant, male-sterile B. napus somatic hybrid 903025 (atrazine sensitive) was produced through protoplast fusion of $B$. oleracea ( $c c$ ) cauliflower line (NY7642A), which carries the Ogura or R1 cms cytoplasm (Dickson, 1985), with $B$. campestris 'Candle' by Le Thi Xuan (Heather, 1993). Cold-tolerant, male-sterile B. napus somatic hybrid 893149 (atrazine resistant) was produced through protoplasm fusion of NY7642A with the atrazine-resistant isoline of B. campestris 'Candle' $\left(\mathrm{BC}_{5}\right)$ by Stephenson (1991). The B. campestris 'Candle' seeds were obtained from W. Beversdorf, Univ. of Guelph, Ont., Canada. Pak choi PI 418988 ( $n=9$; aa; origin China) was obtained from the U.S. Dept. of Agriculture's North Central Regional Plant Introduction Station, Ames, Iowa. Blackrot-resistant Chinese cabbage was produced by Guo et al. (1991). Line 15 originated as a rescued embryo from a cross between $\boldsymbol{B}$. olerace and B. napus (Quazi, 1988). This line was originally reported to be a hexaploid (aacccc). However, the DNA content of F, seed is the same as B. napus, suggesting elimination of the extra $c$ genome. The bridge line was used to improve seed recovery, as direct introgression into Chinese cabbage proved difficult. In this study, all plants received weekly fertilization with a complete soluble fertilizer ( $15 \mathrm{~N}-16 \mathrm{P}-17 \mathrm{~K}$ plus micronutrients) at the rate of $5 \mathrm{~g} \cdot$ liter $^{-1}$ and $16 \mathrm{~h}$ of supplemental fluorescent light $\left(225 \mu \mathrm{mol} \cdot \mathrm{m}^{-2} \cdot \mathrm{s}^{-1}\right)$.

Introgression. For introgression into pak choi, B. napus (aacc) somatic hybrid 903025 was crossed directly with pak choi (aa) PI 418988. All controlled pollinations were made between $\mathrm{O}$ to 2 days after anthesis in a greenhouse at a constant $21 \pm 3 \mathrm{C}$. Allotriploid (aac) $F_{1}$ progeny were then backcrossed to the same pak choi pollen parent, and seed set and ploidy data were recorded. Mean seed set was determined by counting the number of seeds from 20 randomly selected $\mathrm{BC}_{1}$ pods. Ploidy was based on nuclear DNA content, which was analyzed using flow cytometry (Arumuganathan and Earle, 1991).

In the introgression into Chinese cabbage, B. napus (aacc) somatic hybrid 893149 was initially hand-pollinated with bridge line 15 (Quazi, 1988) in a greenhouse. These F, progeny were then open-pollinated with several Chinese cabbage selections carrying black-rot resistance. Two additional backcross generations to the Chinese cabbage selections were carried out in the field using natural pollination vectors.

In both experiments, cold tolerance was assessed by exposing young plants to air at 10C for 2 to 4 weeks. All progeny were nonchlorotic, indicative of the presence of cold-tolerant Brassica chloroplasts that were shown to be present in all parents in previous organellar DNA analyses (Heather, 1993; Stephenson, 199 1). Atrazine resistance was assessed in B. napus somatic hybrid 893149 by swabbing young true leaves with a $1 \%$ atrazine solution. Lack of bleaching indicated the presence of atrazine-resistant Brassica chloroplasts, which agreed with a molecular analysis of the progeny (Stephenson, 1991). Black-rot resistance was assessed by pricking young true leaves with a needle dipped in a 2day-old culture of Xanthomonas campestris pv. campestris grown at $28 \mathrm{C}$. The infected plants were incubated for 7 days at 28C. Male sterility was confirmed by microscopic in- 


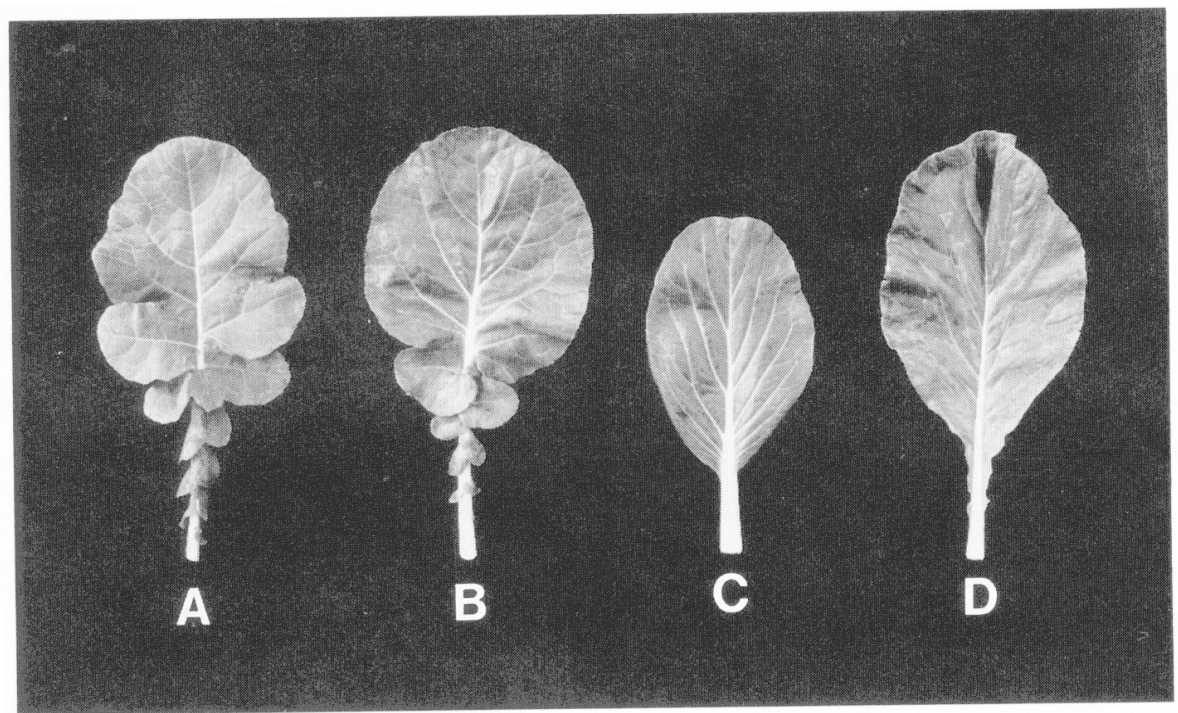

Fig. 1. Mature leaves of (A) Brassica napus L. parent (somatic hybrid 903025; aacc); (B) allotriploid $\mathrm{F}_{1}$ progeny (sac); (C) B. rapa Chinensis Group (PI 41 8988; aa); and (D) diploid $\mathrm{BC}_{1}$ progeny (aa).

spection of the anthers, which were short, shriveled, and did not shed pollen. Observations were also made on flower morphology and nectary development. Good nectary development was indicated by beads of nectar exuded at the base of the flowers.

\section{Results and Discussion}

Pak choi. When pak choi (aa) was crossed directly with $B$. napus (aacc) somatic hybrid 903025, allotriploid (sac) $F_{1}$ progeny were recovered. Leaves of allotriploid plants were morphologically intermediate between the $B$. napus and $B$. campestris Chinensis Group parents (Fig. 1 a-e). Flowers were completely male sterile due to shriveled anthers, which produced no pollen. Other flower parts, including nectaries, were observed to be normal. Diploid B. campestris Chinensis Group plants bearing a closer resemblance to the pak choi parent (Fig. 1d) were recovered after a single backcross of the $\mathrm{F}_{1}$ progeny with pak choi. According to flow cytometry (Table 1), $45 \%$ of the $\mathrm{BC}_{1}$ progeny were diploid, while $35 \%$ remained triploid, and 20910 showed reduc-

Table 1. Nuclear DNA content of $\mathrm{BC}_{1}$ progeny from the cross between Ogura male-sterile allotriploids (sac) and pak choi (aa) Brassica.

\begin{tabular}{lcl}
\hline \hline Plants $(\%)^{y}$ & $\begin{array}{c}\text { DNA content } \\
(\mathrm{pg} / 2 \mathrm{c} \pm \mathrm{SE})\end{array}$ & Interpretation $^{\mathrm{x}}$ \\
\hline $7(35)$ & $1.69 \pm 0.03$ & Triploid (aac) \\
$4(20)$ & $1.41 \pm 0.13$ & $\begin{array}{c}\text { Partial c genome } \\
\text { elimination }\end{array}$ \\
$9(45)$ & $1.07 \pm 0.04$ & \begin{tabular}{c} 
Diploid (aa) \\
\hline
\end{tabular}
\end{tabular}

${ }^{\mathrm{z}}$ Nuclear DNA content (c $=$ haploid, $2 \mathrm{c}=$ diploid) determined by flow cytometry using chicken red blood cells [2.33 picograms (pg)] as an internal control.

Number of plants in $\mathrm{BC}_{1}$ population and percentage of total population in parentheses.

${ }^{x}$ Br-assica napus parent (aacc) of initial cross $=2.32$ pg, B. chinensis $(\mathrm{aa})=1.09 \mathrm{pg}$, and $\mathrm{F}_{1}$ triploids $(\mathrm{aac})$ $=1.71 \mathrm{pg}$. tions in DNA content to levels between triploid and diploid values. The diploid progeny all remained male sterile and cold tolerant. Plants with DNA contents intermediate between diploid and triploid exhibited some abnormal characters, including albino leaf margins, rugose leaf surface, and lack of floral initiation. Allotriploid $\mathrm{F}_{1}$ progeny produced an average of $11.2 \pm 3.3$ seeds/pod. Seed set increased significantly in the second backcross generation $\{[(903025 \mathrm{x}$ 418988) $\mathrm{x}$ 418988] $\times$ 418988), which produced $15.9 \pm$ 1.8 seeds/pod.

Chinese cabbage. For introgression into Chinese cabbage, line 15 (Quazi, 1988) provided a bridge for hand pollinations of $B$. napus somatic hybrid 893149 with Chinese cabbage breeding lines carrying resistance to black rot (Guo et al., 1991). Based on flow cytometric analysis performed on $\mathrm{BC}_{3}$ plants, an average of $30 \%$ of the $\mathrm{BC}_{3}$ population was allotriploid (sac), while $30 \%$ showed partial c genome elimination, and $40 \%$ was diploid (aa). Despite the range of ploidy observed, all progeny exhibited normal vegetative and reproductive development with high female fertility. The $\mathrm{BC}_{3}$ progeny also exhibited stable male sterility with no pollen detected, lack of low-temperature chlorosis, and complete immunity to black rot as evidenced by no lesion formation on infected leaves after 7 days incubation.

In summary, cold-tolerant Ogura cms was successfully incorporated into pak choi and Chinese cabbage from somatic hybrid rapeseed using two strategies; both resulted in rapid transfer of the desired traits with maintenance of female fertility. In the case of introgression into pak choi, flow cytometry allowed rapid identification of aneuploids, increasing breeding efficiency. The Ogura cms system is an attractive method for hybrid seed production in that it appears stable from observations made by us and from previous work (Bartkowiak-Broda et al., 1979). Further, the system is especially useful for all Brassica vegetable species because no fertility restoration is required.

\section{Literature Cited}

Arumuganathan, K. and E.D. Earle. 1991. Estimation of nuclear DNA amounts of plants by flow cytometry. Plant Mol. Biol. Rptr. 9:229-241.

Bannerot, H., L. Boulidard,Y. Cauderon, and J. Temple. 1974. Cytoplasmic male sterility transfer from Raphanus to Brassica. Proc. Eucarpia Mtg.-Cruciferae Crop Section 25:52-54.

Bartkowiak-Broda, L, P. Rousselle, and M. Renard. 1979. Investigations of two kinds of cytoplasmic male sterility in rapeseed (Brassica napus L.). Genet. Polonica 20487-497.

Dickson, M.H. 1985. Male sterile persistent white curd cauliflower NY7642A and its maintainer NY7642B. HortScience 20:957.

Guo, H., M.H. Dickson, and J.E. Hunter. 1991. Brassica napus sources of resistance to black rot in crucifers and inheritance of resistance. HortScience 26:1545-1547.

Hanson, M.R. and M.F. Conde. 1985. Functioning and variation of cytoplasmic genomes: Lessons from cytoplasmic-nuclear interactions affecting male fertility in plants. Intl. Rev. Cytol. 94:213-245.

Heather, D.W. 1993. Fatty acid modification and other improvements in rapeseed (Brassica napus L.) through sexual and somatic hybridization. PhD Diss., Cornell Univ., Ithaca, N.Y.

Jarl, C.I., M.Q.J.M. van Grinsven, and F. van den Mark. 1989. Correction of chlorophyll-defective male-sterile winter oil seed rape (Brassica napus) through organelle exchange: Molecular analysis of the cytoplasm of parental lines and corrected progeny. Theor. Appl. Genet. 77: 135141.

Jourdan, P.S. and E.D. Earle. 1989. Genotypic variability in the frequency of plant regeneration from leaf protoplasts of four Brassica spp. and Raphanus sativus. J. Amer. Soc. Hort. Sci. 114:343-349.

Jourdan, P. S., E.D. Earle, and M.A. Mutschler. 1989. Synthesis of male sterile, triazine-resistant Brassica napus by somatic hybridization between cytoplasmic male sterile $B$. oleracea and atrazine-resistant B. campestris. Theor. Appl. Genet. 78:445-455.

Ogura, H. 1968. Studies on the new male sterility in Japanese radish, with special references to the utilization of this sterility towards the practical raising of hybrid seeds. Memoirs Fat. Agr. Kagoshima Univ. 6:39-78.

Pelletier, G., C. Primard, F. Vedel, P. Chetrit, R. Remy, P. Rousselle, and M. Renard. 1983. Intergeneric cytoplasmic hybridization in Cruciferae by protoplasm fusion. Mol. Gen. Genet. 191:244250.

Quazi, M.H. 1988. Interspecific hybrids between Brassica napus L. and B. oleracea L. developed by embryo culture. Theor. Appl. Genet. 75:309318 .

Rousselle, P. 1982. Initial results of a program to introduce Ogura cytoplasmic male sterility from radish into rapeseed. Agronomy (Paris) 2:859864.

Shiga, T. 1970. Rape breeding by interspecific crossing between Brassica napus and B. campestris in Japan. Jpn. Agr. Res. Quarterly 5:5-10.

Stephenson, J.C. 1991. The effect of gamma irradiation on protoplasm fusion between atrazine-resistant Brassica campestris and Ogura male sterile B. oleracea. MS Thesis, Cornell Univ., Ithaca N.Y. 